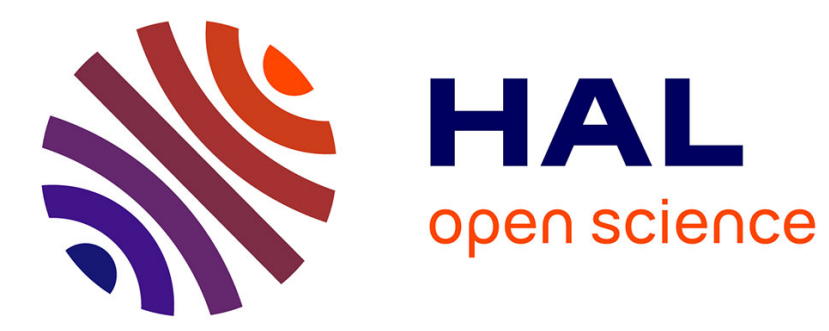

\title{
Spinal control of erection by glutamate in rats
}

Olivier Rampin, Régine Monnerie, Nathalie Jerome, K. Mckenna, Yves Maurin

\section{To cite this version:}

Olivier Rampin, Régine Monnerie, Nathalie Jerome, K. Mckenna, Yves Maurin. Spinal control of erection by glutamate in rats. AJP - Regulatory, Integrative and Comparative Physiology, 2004, 286, pp.R710-R718. hal-02679626

\section{HAL Id: hal-02679626 \\ https://hal.inrae.fr/hal-02679626}

Submitted on 31 May 2020

HAL is a multi-disciplinary open access archive for the deposit and dissemination of scientific research documents, whether they are published or not. The documents may come from teaching and research institutions in France or abroad, or from public or private research centers.
L'archive ouverte pluridisciplinaire HAL, est destinée au dépôt et à la diffusion de documents scientifiques de niveau recherche, publiés ou non, émanant des établissements d'enseignement et de recherche français ou étrangers, des laboratoires publics ou privés. 


\title{
Spinal control of erection by glutamate in rats
}

\author{
Olivier Rampin, ${ }^{1}$ Régine Monnerie, ${ }^{2}$ Nathalie Jérôme, ${ }^{1}$ Kevin McKenna, ${ }^{3}$ and Yves Maurin ${ }^{1}$ \\ ${ }^{1}$ Analyse et Modélisation en Imagerie Biologique, ${ }^{2}$ Neurobiologie de l'Olfaction et de la Prise \\ Alimentaire, Institut National de la Recherche Agronomique, 78352 Jouy-en-Josas Cedex, France; \\ and ${ }^{3}$ Department of Physiology, Northwestern University Medical School, Chicago, Illinois 60611-3010
}

\begin{abstract}
Rampin, Olivier, Régine Monnerie, Nathalie Jérôme, Kevin McKenna, and Yves Maurin. Spinal control of erection by glutamate in rats. Am J Physiol Regul Integr Comp Physiol 286: R710-R718, 2004. First published December 18, 2003; 10.1152/ ajpregu.00645.2003.-The lumbosacral spinal network controlling penile erection is activated by information from peripheral and supraspinal origins. We tested the hypothesis that glutamate, released by sensory afferents from the genitals, activates this proerectile network. In anesthetized intact and T8 spinalized (i.e., freed from supraspinal inhibition) male rats, the parameters of electrical stimulation of the dorsal penile nerve (DPN) that elicited intracavernous pressure (ICP) rises were determined. In T8 spinalized rats, DPN stimulations were applied in the presence of $\mathrm{D}(-)$-2-amino-5-phosphonopentanoic acid (D-AP5), a competitive NMDA receptor antagonist, or of 2,3-dioxo6-nitro-1,2,3,4-tetrahydrobenzo[f]quinoxaline-7-sulphonamide (NBQX), an AMPA-kainate receptor antagonist, injected intrathecally at the lumbosacral level. Both antagonists, alone or in combination, dose dependently decreased the ICP rise and increased its latency. In conscious rats, reflexive erections were depressed by D-AP5 and NBQX, as revealed by an increased latency of the first erection and by decreases of the number of rats displaying erections, of the number of erection clusters and of the number of erections per cluster. In anesthetized rats, the combined administration of the glutamatergic agonists NMDA and AMPA elicited ICP rises in the absence of DPN stimulation. In contrast, both agonists moderately decreased the ICP rise elicited by DPN stimulation but did not affect its latency. These results support our hypothesis that glutamate, released on stimulation of the genitals and acting at AMPA and NMDA receptors, is a potent activator of the spinal proerectile network.
\end{abstract}

urogenital; sexual reflexes; lumbosacral spinal cord

ERECTION IS CAUSED by the simultaneous increase of blood flow to the penis and active relaxation of the erectile tissue of the corpora cavernosa and the corpus spongiosum (1). Both mechanisms are controlled by the autonomic nervous system.

In conscious rats, retraction of the penile sheath elicits reflexive erections $(14,32)$ that are accompanied by penile pressure rises $(5,33)$. In anesthetized rats, intracavernous pressure (ICP) rises are reflexively elicited by stimulation of the dorsal penile nerve (DPN) $(27,29,35)$. Reflexive erections rely on a reflex loop that includes a network of lumbosacral spinal neurons as a link between the DPN as the afferent limb and the sacral parasympathetic outflow as the efferent limb. The DPN conveys sensory information from the penis and perigenital skin to the lumbosacral cord $(23,26)$. Its stimulation activates a network of lumbosacral neurons (30). In rats, the proerectile parasympathetic outflow originates in the sacral parasympathetic nucleus (SPN) of the L6-S1 spinal cord (28). The SPN contains the preganglionic neurons that innervate the

Address for reprint requests and other correspondence: O. Rampin, Analyse et Modélisation en Imagerie Biologique, bâtiment 325, Institut National de la Recherche Agronomique, 78352 Jouy-en-Josas Cedex, France (E-mail: olivier.rampin@jouy.inra.fr). penis (21). The neurotransmitters that activate the spinal proerectile network are presently unknown.

The role of glutamate in the spinal control of the urinary and the lower digestive tracts has been established. In the rat, the NMDA glutamate receptor subtype is involved in a lumbosacral inhibitory mechanism controlling bladder activity $(36,38)$, whereas the AMPA-kainate subtype controls 1) the activation of spinal neurons induced by colorectal distension (16) and 2) the frequency of spontaneous and perineal stimulation-evoked bladder contractions (36). Thus NMDA and AMPA-kainate receptors participate to the spinal control of pelvic organs. Anatomically, both AMPA receptors (8) and NMDA receptors (13) are present in the rat lumbosacral spinal cord. In the present study, we tested the hypothesis that glutamate participates to the activation of the spinal proerectile network through NMDA and AMPA glutamatergic receptors.

\section{MATERIALS AND METHODS}

Animals. Adult male Sprague-Dawley rats weighing 250-400 g were purchased from Charles River (Saint-Aubin les Elbeuf). Rats were housed by groups of four in plastic cages containing wood chip bedding. They had free access to commercial pelleted rodent chow (Usine d'Aliments Rationnels) and tap water. Rats were placed in an animal facility with temperature at $22^{\circ} \mathrm{C}$ and kept on a $12: 12-\mathrm{h}$ light-dark cycle (lights on at $8 \mathrm{AM}$ ). All experiments were carried out in accordance with the European Economical Community Directive of November 24th 1986 (86/609/EEC) on the use of laboratory animals. All efforts were made to minimize animal suffering and to reduce the number of animals used.

Implantation of an intrathecal catheter to be used in conscious rats. Rats were anesthetized with pentobarbital sodium $(60 \mathrm{mg} / \mathrm{kg}$ ip, Sanofi-SynthéLabo, Garches, France). Intrathecal (it) catheterization was performed as reported by LoPachin and coworkers (19). The rat's head was placed in a stereotaxic frame and was rotated nose downward to facilitate catheter insertion. The catheter, a polyethylene tubing PE-10 stretched to $150 \%$ of its original length in hot water, was cut to the required length so that its distal opening reached the L4-L6 segments of the spinal cord. The skin and neck muscles were incised and retracted. The atlanto-occipital membrane was opened, and the catheter, flushed with sterile $\mathrm{NaCl} 0.9 \%$, was carefully advanced in the caudal direction. The catheter was connected to a Hamilton syringe filled with saline to prevent cerebrospinal fluid leakage. Rats were allowed to recover from surgery for $1 \mathrm{wk}$. Rats were distributed in two groups, one group receiving only D-AP5 $(n=8)$ and the other only $\operatorname{NBQX}(n=8)$. During one test, a given rat received one injection of either saline or 10 or $100 \mu \mathrm{g}$ of one compound. Successive tests were separated by a period of at least 2 days. The experiment ended when each rat had received three injections: one of saline and one of each dose of the tested compound.

DPN stimulation and drug injection in anesthetized rats. Rats were anesthetized with urethane $(1.2 \mathrm{~g} / \mathrm{kg}$ ip in sterile water) and their

The costs of publication of this article were defrayed in part by the payment of page charges. The article must therefore be hereby marked "advertisement" in accordance with 18 U.S.C. Section 1734 solely to indicate this fact. 
temperature was maintained at $37^{\circ} \mathrm{C}$ using an homeothermic blanket. In some rats, we performed a section of the spinal cord before the experiments. The skin and muscles over the midthoracic vertebrae were incised. The T8 spinal cord was exposed through a laminectomy of the T7-T8 vertebrae. The dura was incised, and a complete transversal section of the underlying T8 spinal cord was performed. Rats were tracheotomized. The carotid artery was catheterized with polyethylene tubings filled with heparinized saline $(25 \mathrm{U} / \mathrm{ml})$ to record blood pressure (BP) via a pressure transducer (Elcomatic 750, Glasgow, UK). The penis was catheterized using a 25-gauge needle connected to a polyethylene tubing filled with heparinized saline and connected to a pressure transducer, allowing for ICP recording as described previously (12).

Pressure signals were converted into potentials (V), digitized, sampled at a rate of $5 \mathrm{~Hz}$ (Axotape, Axon Instruments, Union City, CA) and stored in a microcomputer for offline analysis. The left DPN was exposed at the dorsal aspect of the penis and freed from surrounding connective tissue $5 \mathrm{~mm}$ distal to the pubic symphysis and placed on bipolar stainless steel electrodes. Stimulations were delivered using an electrical stimulator (model 2100, A-M Systems, Carlsborg, WA).

For intrathecal injections, implantation of the intrathecal catheter was performed just before the spinal transection as mentioned above. Compounds were dissolved in $\mathrm{NaCl} 0.9 \%$, and $10 \mu \mathrm{l}$ of the solution was injected within 10-20 s, immediately followed by a flush of $10 \mu \mathrm{l}$ $\mathrm{NaCl} 0.9 \%$. Electrical stimulation of the DPN was performed $10 \mathrm{~min}$ after intrathecal injections. When cumulative injections of drugs were used, consecutive injections were separated by a 15 -min period.

Reflexive erection tests. Eight male rats, selected for displaying reflexive erections on retraction of the penile sheath in preliminary tests, were used. To record the reflex, animals were restrained on their backs in a plastic cylinder ( $8 \mathrm{~cm}$ diameter $\times 20 \mathrm{~cm}$ length) for a 5-min adaptation period. Then the penile sheath was tonically retracted with a loose metal loop. Reflex responses were visually identified and scored as erections when lengthening of the penile body, glans engorgement involving some dilation of the glans, cups (glans erection with flaring of the glans extremity), and flips (dorsiflexions of the penile body) occurred (14). We did not distinguish between these different penile responses in the present experiments. Tests lasted for 15 min starting from the first reflexive erection or were stopped 15 min after penile sheath retraction if no erection occurred.

At the end of all experiments, rats were killed with a lethal dose of urethane. Ten microliters of methylene blue was injected intrathecally and flushed with $10 \mu \mathrm{l}$ of $\mathrm{NaCl} 0.9 \%$. The spinal cord was then exposed, and the exact location of the caudal tip of the catheter (revealed by the presence of methylene blue) was carefully recorded. Only rats with a catheter tip facing the L5-S1 segments were considered. Diffusion of methylene blue from the tip of the catheter revealed that spinal levels exposed to the injected drugs extended approximately from one segment rostrally to one segment caudally, relative to the segment facing the tip of the catheter.

Data analysis. In the first series of experiments, the amplitude of the ICP rise elicited by various DPN stimulation parameters in anesthetized rats was measured using the ICP/BP ratio. In the second series, the effects of intrathecal injection of various antagonists and agonists of glutamate on either basal ICP or the ICP rise elicited by DPN stimulation were measured using latency of the ICP rise, expressed in seconds, the value of ICP itself, and the ICP/BP ratio. In the third series of experiments, the effects of intrathecal injection of glutamate antagonists on reflexive erections in conscious rats were measured using the number of rats displaying at least one reflexive erection, the latency of the first erection, the total number of erections, the number of erection clusters, and the number of erections per cluster.

Comparison of the effects of DPN stimulation between intact and T8 rats was performed using the Student's $t$-test, and differences were considered statistically significant when $P<0.05$. The effects of the various compounds were analyzed using one-way repeated-measures ANOVA. All pairwise multiple comparison procedures were further performed using the Holm-Sidak method when ANOVA revealed a statistical difference, i.e., with $P<0.05$. When the data did not comply with a normal distribution (as evaluated by a KolmogorovSmirnov test) or with the equal variance test, a Friedman repeatedmeasures ANOVA on ranks was performed. In case of statistical significance, all pairwise multiple comparison procedures were done using the Dunn's method.

The comparison of the various compounds alone or in combination were performed using two-way repeated-measures ANOVA with ICP/BP as the dependent variable. In this case, for each rat, the $\mathrm{ICP} / \mathrm{BP}$ value in the control condition (i.e., on vehicle injection) was considered as the $100 \%$ value, and the ICP/BP values subsequently measured with the different doses of drugs were expressed as a percentage of this control. All pairwise multiple comparisons were then carried out as described above.

Drugs. Urethane was purchased from Sigma (Saint-Quentin-Fallavier, France). NMDA, AMPA hydrobromide, D(-)-2-amino-5-phosphonopentanoic acid (D-AP5), and 2,3-dioxo-6-nitro-1,2,3,4-tetrahydrobenzo[f]quinoxaline-7-sulfonamide (NBQX) disodium were purchased from Tocris (Fisher Bioblock Scientific, Illkirch, France) and dissolved to the required concentration in $\mathrm{NaCl} 0.9 \%$.

\section{RESULTS}

DPN stimulation in anesthetized animals. Five different stimulation amplitudes $(0.5,1,2,5$, and $10 \mathrm{~V})$, three frequencies $(2,5$, and $10 \mathrm{~Hz})$, and two pulse widths $(0.1$ and $1 \mathrm{~ms})$ were tested, for a total of 30 different combinations. Each one of eight intact and eight T8 rats received all of the 30 stimulation conditions. Among the group of intact rats, five animals exhibited at least one erection (ICP rise) in response to at least one stimulation condition. We recorded responses for only 11 of 30 stimulation conditions. Among these 11 sets, only two elicited responses in three of eight rats tested. For these two sets, the SE reached 24.5 and $23.7 \%$ of the value of the mean.

In the T8 group, all the rats displayed at least one erection. Responses were observed for 25 of 30 stimulation conditions, and for 16 of them, between three and seven rats responded with an average SE of $13.16 \%$ of the value of the mean.

The mean $( \pm \mathrm{SE})$ number of erections displayed by the responders in the group of intact rats was significantly lower than that displayed by the T8 rats $(3.4 \pm 1.1$ vs. $11.1 \pm 2.2$, respectively, $P=0.023)$. So was the ICP rise elicited by DPN stimulation (intact rats: $25.9 \pm 4.4 \mathrm{mmHg}$; T8 rats: $46.8 \pm 4.7$ $\mathrm{mmHg}, P=0.012$ ) and the ICP/BP ratio (intact rats: $0.30 \pm$ 0.09; T8 rats: $0.78 \pm 0.08, P=0.0024)$.

Figure 1 summarizes the effects of DPN stimulation at the different parameters combinations on ICP/BP ratio in intact and $\mathrm{T} 8$ rats. The latter ones responded more consistently than the former ones. Moreover, the stimulation range that elicited an increase of the ICP/BP ratio was wider in T8 rats than in intact ones. Thus, in subsequent experiments, the selected paradigm was $\mathrm{T} 8$ rats and stimulations at $5-\mathrm{V}$ amplitude, $5-\mathrm{Hz}$ frequency, and 1-ms pulse duration for $30 \mathrm{~s}$.

Effects of intrathecal injection of glutamate antagonists on the ICP rise elicited by DPN stimulation. As shown on Fig. 2A, increasing amounts $(1,10$, and $100 \mu \mathrm{g})$ of D-AP5 decreased the ICP rise induced by DPN stimulation. Because, during the experiment, the blood pressure did not change markedly, the value of the ICP/BP ratio also decreased. Similar results were achieved with the same doses of NBQX (Fig. 2B) and with the combined injection of both antagonists (Fig. 2C). 
Fig. 1. Relation between intracavernous pressure (ICP) and parameters of dorsal penile nerve (DPN) stimulation. Experiments were performed in anesthetized rats, either intact $(A$ and $B)$ or T8 spinalized $(C$ and $D)$. The rise of ICP was expressed as the increase of the ICP/ blood pressure (BP) ratio induced by various parameters (amplitude, frequency, and width) of DPN electrical stimulation (30-s duration). As revealed by the comparison between bottom and top histograms, $\mathrm{T} 8$ rats displayed a greater number of erections (regardless of stimulation parameters) and greater ICP/BP increases compared with intact rats. Thus, in subsequent experiments, T8 spinalized rats were used and DPN was stimulated at $5 \mathrm{~V}, 5 \mathrm{~Hz}, 1 \mathrm{~ms}$ for $30 \mathrm{~s}$, as indicated by the asterisk (*).
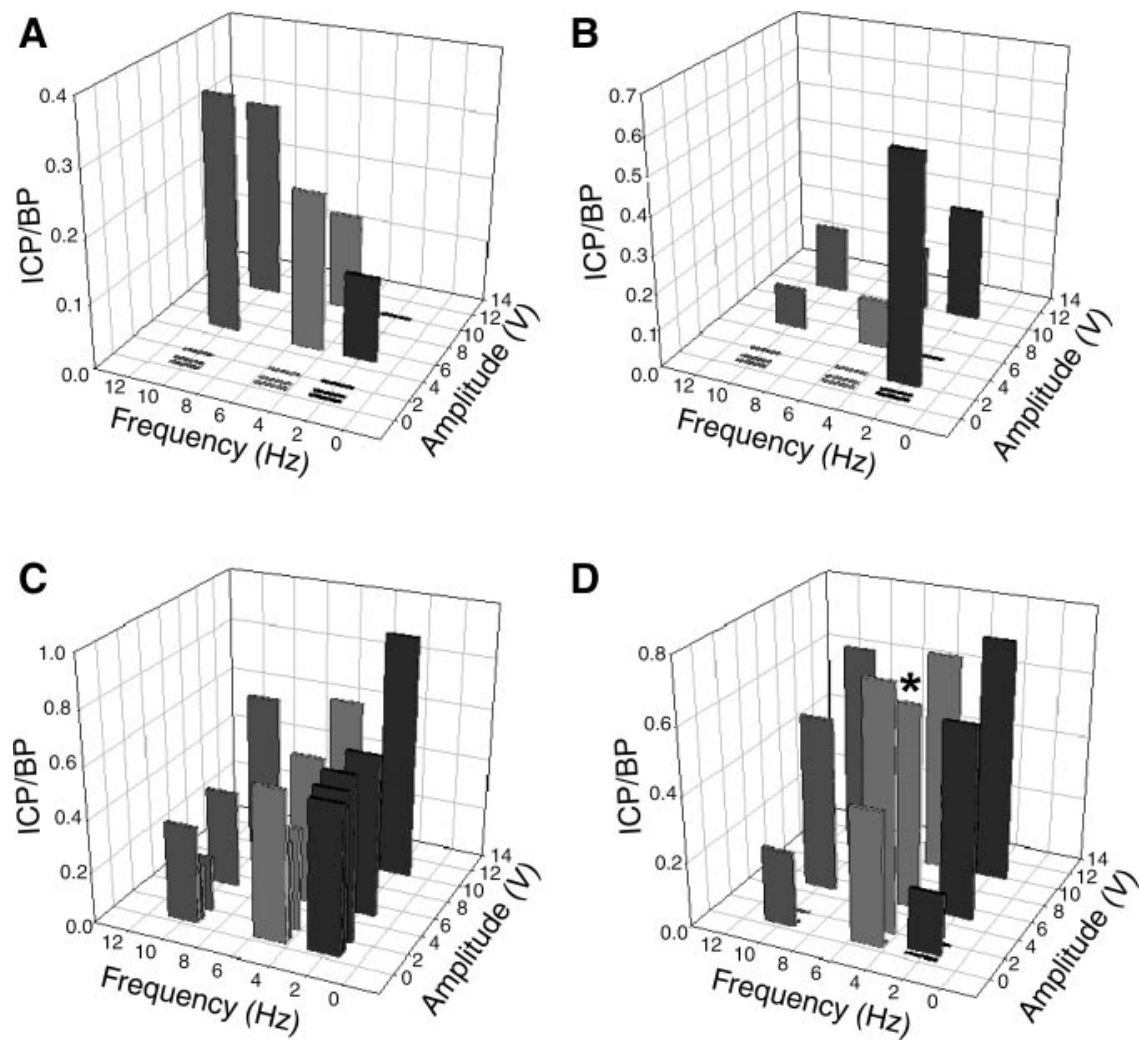

The results are summarized in Fig. 3, which shows that both antagonists, alone or in combination, significantly decreased the ICP/BP ratio: $[F(3,27)=28.99, P<0.001]$ for $\mathrm{D}-\mathrm{AP} 5$; $[F(3,27)=21.36, P<0.001]$ for $\mathrm{NBQX}$ and $[F(3,27)=$ 42.251, $P<0.001]$ for D-AP5 +NBQX.

This inhibitory effect was dose dependent for both drugs. For D-AP5, each dose was significantly different from the control group $(P<0.001)$. The dose of $1 \mu \mathrm{g}$ was different from $10 \mu \mathrm{g}(P=0.015)$ and from $100 \mu \mathrm{g}(P<0.001)$. The dose of $10 \mu \mathrm{g}$ was different from $100 \mu \mathrm{g}(P=0.049)$. For NBQX, 10 and $100 \mu \mathrm{g}$ doses were significantly different from the control group $(P<0.001)$, whereas $1 \mu \mathrm{g}$ dose was not. The dose of $1 \mu \mathrm{g}$ was different from $10 \mu \mathrm{g}(P=0.004)$ and from $100 \mu \mathrm{g}(P<0.001)$. The dose of $10 \mu \mathrm{g}$ was different from 100 $\mu \mathrm{g}(P=0.009)$.

When D-AP5 and NBQX were injected in combination, each dose elicited a significant decrease of the ICP/BP ratio compared with the control group $(P<0.001)$. The decrease induced by the dose of $1 \mu \mathrm{g}$ was also different from that induced by 10 and $100 \mu \mathrm{g}(P<0.001)$. No difference was detected between the effects elicited by 10 and $100 \mu \mathrm{g}$.

Figure 3 also shows that the decrease of the ICP/BP ratio is antagonist dependent $[F(2,83)=7.076, P=0.005], \mathrm{NBQX}$ being less potent than D-AP5 alone $(P=0.003)$ or D-AP5 +NBQX $(P=0.006)$. The combination of both antagonists was not more potent than D-AP5 alone $(P=0.767)$.

Effects of intrathecal injection of glutamate antagonists on the latency of the ICP rise elicited by DPN stimulation. The results are displayed on Fig. 4. The NMDA antagonist D-AP5 had no effect $[F(3,26)=1.132, P=0.364]$. The AMPA antagonist NBQX significantly increased the latency $[F(3,26)=4.761, P=0.014]$ as did the combination of the two antagonists $[F(3,27)=4.507, P=0.016]$. Only the 100 $\mu \mathrm{g}$ dose of NBQX and of the combination of both antagonists significantly increased this parameter: for NBQX, 100 vs. 0 $\mu \mathrm{g}, P=0.003,100$ vs. $1 \mu \mathrm{g}, P=0.006$, and 100 vs. $10 \mu \mathrm{g}$, $P=0.032$; for the combination of antagonists, 100 vs. $0 \mu \mathrm{g}$, $P=0.004,100$ vs. $1 \mu \mathrm{g}, P=0.007$.

Effects of $D-A P 5$ or $N B Q X$ on reflexive erections in conscious rats. The effects of the two antagonists are displayed on Fig. 5. On vehicle injection, all rats displayed reflexive erections in response to penile sheath retraction. One-way ANOVAs revealed that D-AP5 and NBQX decreased the number of responders (100 $\mu \mathrm{g}$ D-AP5: $P=0.002 ; 100 \mu \mathrm{g}$ NBQX: $P<0.05)$, increased the latency of the first erection $(100 \mu \mathrm{g}$ D-AP5: $P<0.001 ; 10 \mu \mathrm{g}$ NBQX: $P=0.002 ; 100 \mu \mathrm{g}$ NBQX: $P<0.001)$, decreased the total number of erections $(100 \mu \mathrm{g}$ D-AP5: $P=0.003 ; 100 \mu \mathrm{g}$ NBQX: $P=0.003)$, and decreased the number of clusters $(100 \mu \mathrm{g}$ D-AP5: $P=0.001 ; 100 \mu \mathrm{g}$ NBQX: $P=0.002)$. In addition, only D-AP5 exhibited a significant dose-dependent effect on the number of erections per cluster $(10 \mu \mathrm{g}: P=0.028 ; 100 \mu \mathrm{g}: P=0.002)$.

Effects of intrathecal injection of glutamatergic agonists on $I C P, B P$, and the ICP/BP ratio in the absence of DPN stimulation. At variance with the results obtained with antagonists, the intrathecal injection of the glutamatergic agonists NMDA and AMPA affected blood pressure. Therefore, we analyzed separately their effects on BP, ICP, and ICP/BP.

Figure 6 shows original recordings of $\mathrm{BP}$ and ICP after the injection of either NMDA (Fig. 6A), AMPA (Fig. 6B), or NMDA+AMPA (Fig. 6C). The blood pressure (BP, Fig. 6, top traces) was increased by NMDA and AMPA, either alone or in combination, as also shown in Table 1. 


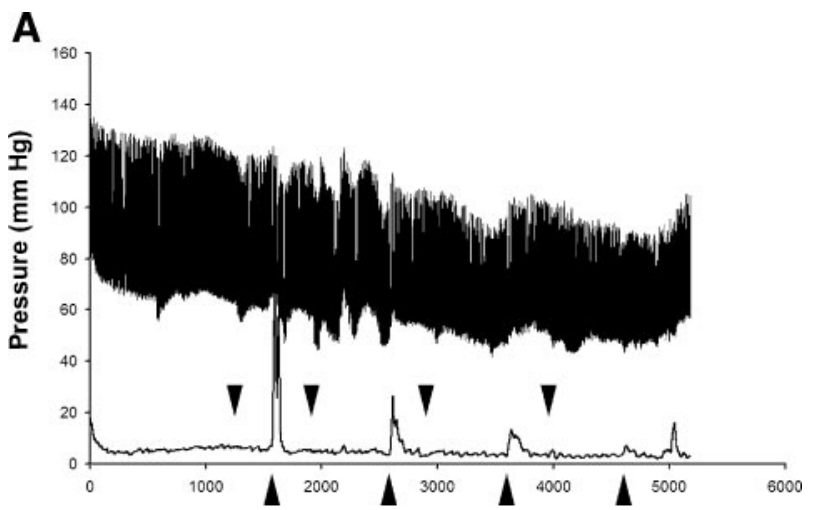

B
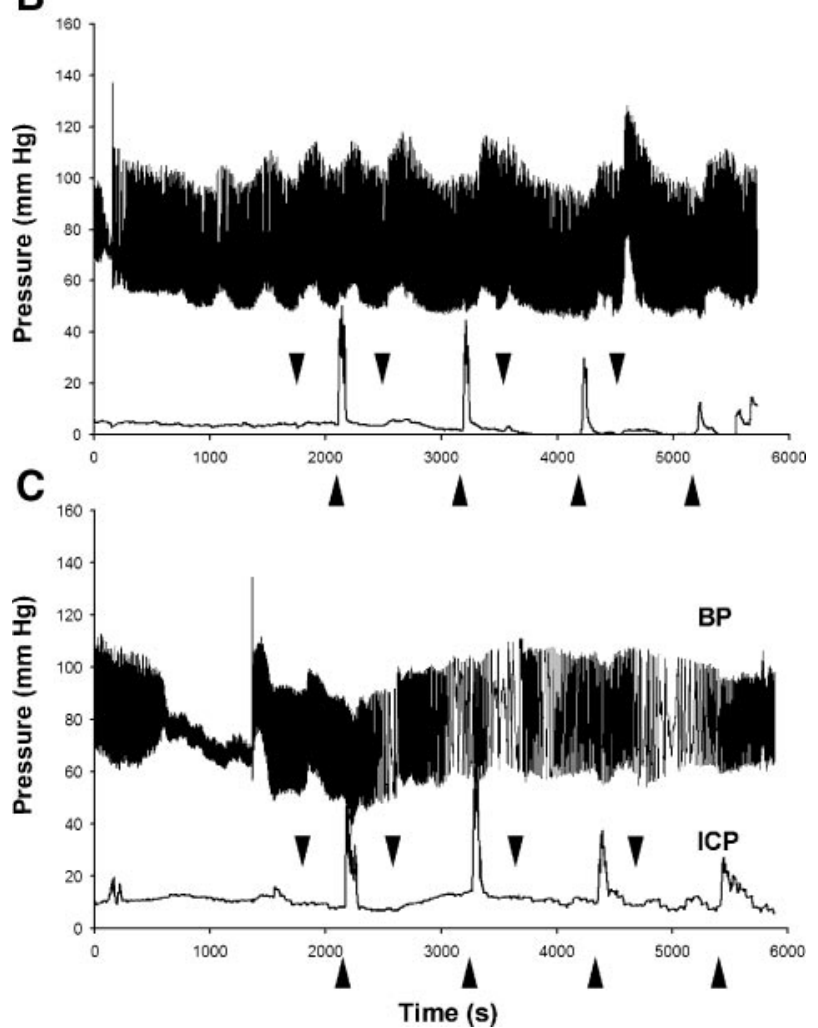

Fig. 2. Effects of the intrathecal injection of the glutamatergic antagonists D(-)-2-amino-5-phosphonopentanoic acid (D-AP5; $A$ ) and 2,3-dioxo-6-nitro1,2,3,4-tetrahydrobenzo[f]quinoxaline-7-sulphonamide (NBQX; $B$ ) on BP and ICP. Each recording represents 1 experiment, carried out on a separate animal, showing the BP (top trace) and the ICP (bottom trace). Antagonists were administered alone $(A$ and $B)$ or in combination $(C)$. Downward arrowheads (above ICP traces) represent the start of the successive intrathecal injections of 0 (leftmost arrowhead), 1, 10, and $100 \mu \mathrm{g}$ (rightmost arrowhead) of each compound. Upward arrowheads (below $x$-axis) represent the start of electrical stimulation of the DPN ( $5 \mathrm{~V}, 5 \mathrm{~Hz}, 1 \mathrm{~ms}, 30 \mathrm{~s})$. Stimulation of DPN elicited ICP rises, which were inhibited by increasing doses of the antagonists.

The combined injection of both agonists provided results similar to those of AMPA alone [Table 1, $F(3,23)=41.824$, $P<0.001]$, with the difference that the dose of $1 \mu \mathrm{g}$ reached statistical significance (1 $\mu \mathrm{g}$ vs. vehicle: $P=0.016)$.

The effects of NMDA and AMPA on the ICP/BP ratio are summarized in Fig. 7.

The former agonist, administered alone, was devoid of any effect $\left(\chi^{2}=6.913\right.$, df $\left.=3, P=0.075\right)$, despite the slight but not significant increase at $100 \mu \mathrm{g}$. On the contrary, the latter

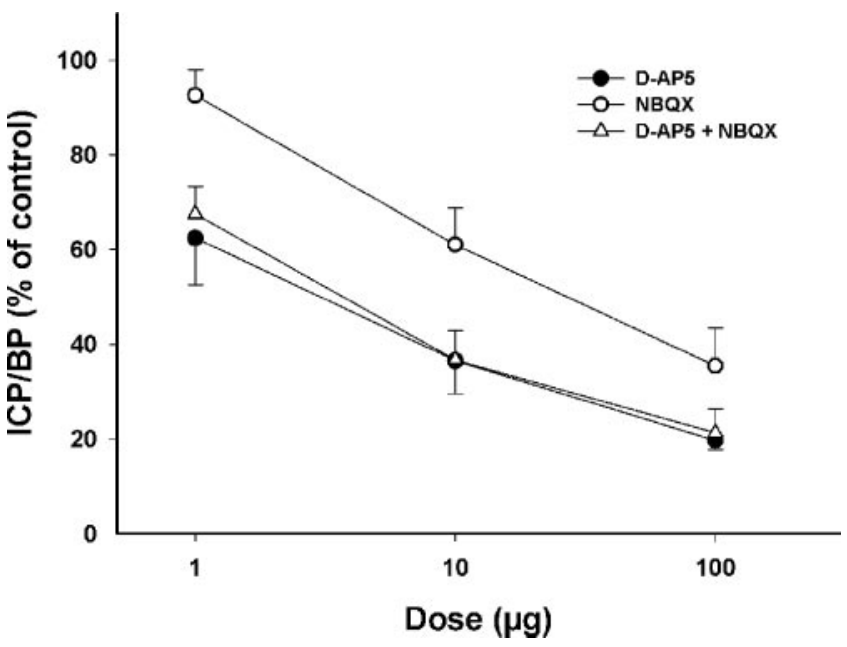

Fig. 3. Effects of the glutamatergic antagonists D-AP5 and NBQX on the ICP rise elicited by DPN electrical stimulation. Data are expressed as means \pm SE of the percentage of the control ICP/BP value (measured after vehicle injection). Control values were $0.95 \pm 0.13(n=7)$ for D-AP5, $1.12 \pm 0.11(n=$ 7) for NBQX, and $1.33 \pm 0.11(n=7)$ for D-AP5+NBQX.

had a significant effect $[F(3,27)=4.858, P=0.012]$ due to a $40 \%$ increase at $100 \mu \mathrm{g}$ relative to the control value $(P=$ 0.006). Their combination also increased the ICP/BP ratio $[F(3,22)=4.819, P=0.017]$. Two-way ANOVAs revealed a statistically significant difference $[F(2,78)=4.733, P=$ 0.023 ] between the effect of the combination of both agonists and the effect of either of them administered alone (AMPA+NMDA vs. AMPA alone $P=0.011$; AMPA+NMDA vs. NMDA alone $P=0.021$; AMPA vs. NMDA $P=0.756$ ).

Finally, the effects of the combined injection of AMPA and NMDA (1-100 $\mu \mathrm{g}$ ) were completely abolished (neither ICP nor $\mathrm{BP}$ rises) by the combined administration of $100 \mu \mathrm{g}$ D-AP5 and NBQX (data not shown).

Effects of intrathecal injection of glutamate agonists on ICP, $B P$, and the ICP/BP ratio during $D P N$ stimulation. As shown on Table 2, only $100 \mu \mathrm{g}$ of either NMDA or AMPA alone

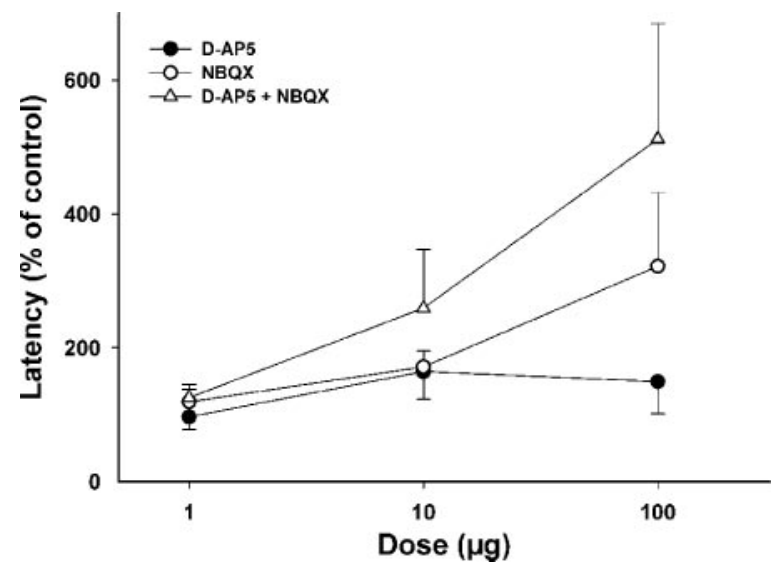

Fig. 4. Effects of the glutamatergic antagonists D-AP5 and NBQX on the latency of the ICP rise elicited by DPN electrical stimulation. Data are expressed as means $\pm \mathrm{SE}$ of the percentage of the control latency value (measured after vehicle injection). Control values were $10.9 \pm 2.9 \mathrm{~s}(n=7)$ for D-AP5, $14.9 \pm 2.2 \mathrm{~s}(n=7)$ for NBQX, and $9.6 \pm 1.6 \mathrm{~s}(n=7)$ for D-AP5 +NBQX. See text for statistical analysis. 
A

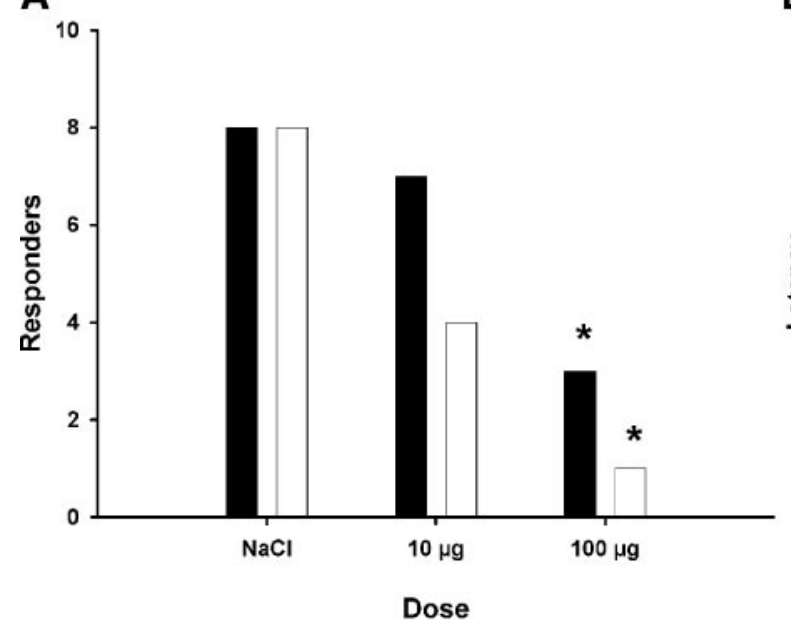

C

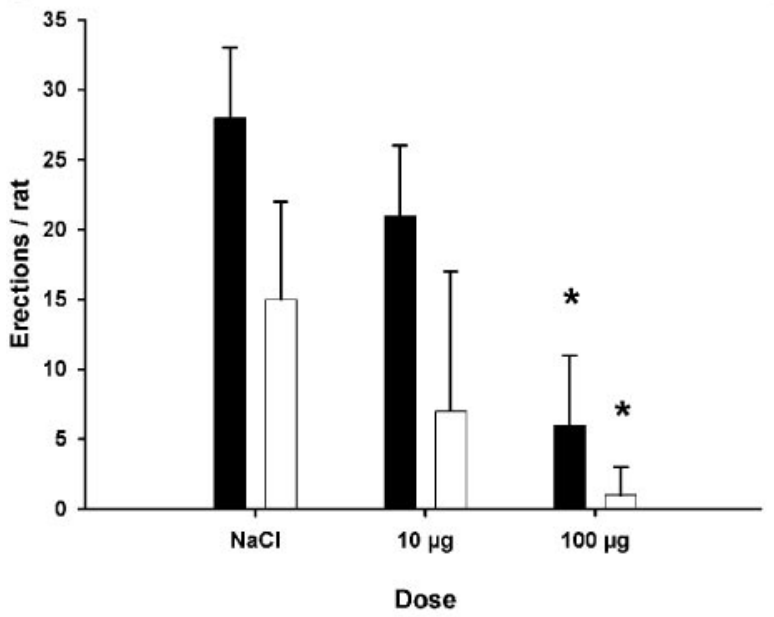

B

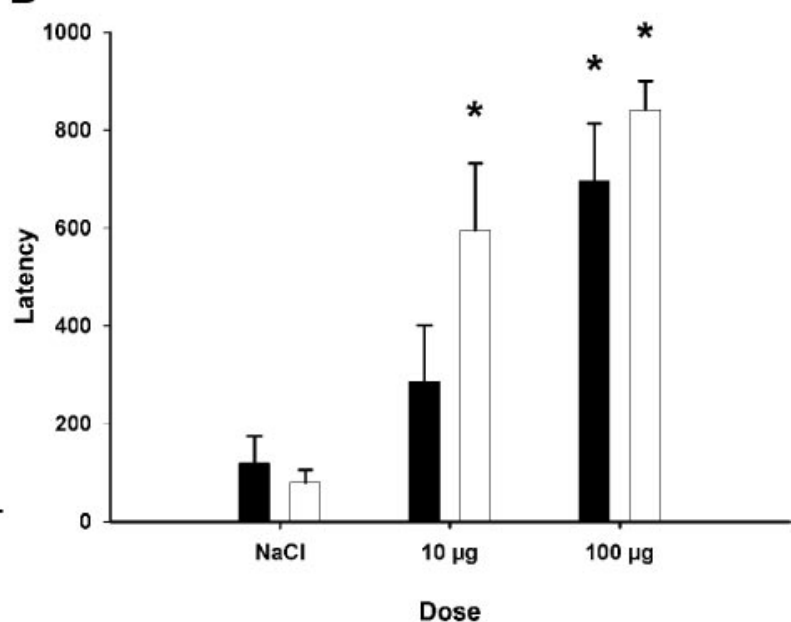

D

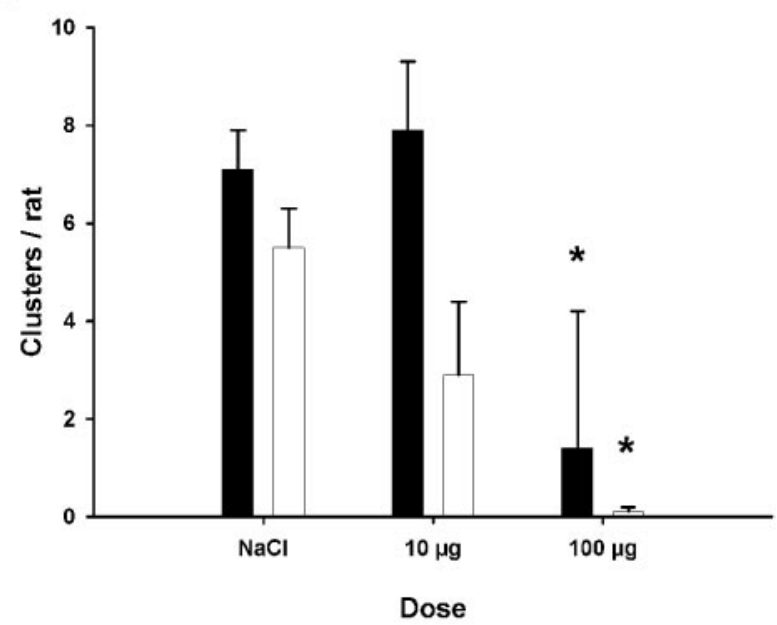

E

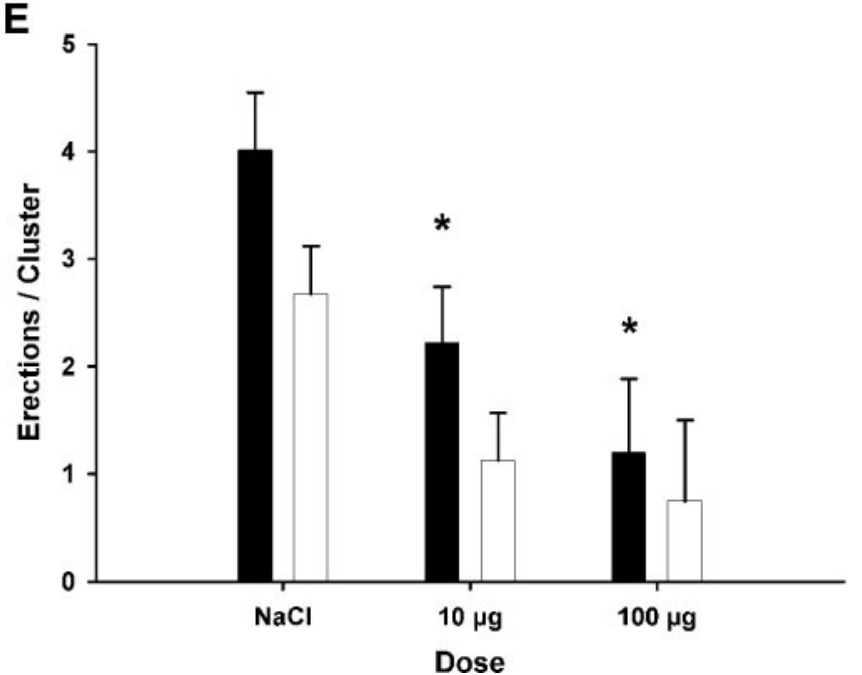

Fig. 5. Effects of the glutamatergic antagonists D-AP5 and NBQX on reflexive erections in conscious rats. Eight animals were used per compound. Only the doses of 10 and $100 \mu \mathrm{g}$ were tested in this paradigm. $A$ : number of responding animals; $B$ : latency of first erection; $C$ : total number of erections; $D$ : number of erection clusters; $E$ : number of erections per cluster. Filled bars: D-AP5; open bars: NBQX. *Statistically different from the value upon $\mathrm{NaCl}$ injection (see text for significance level). 

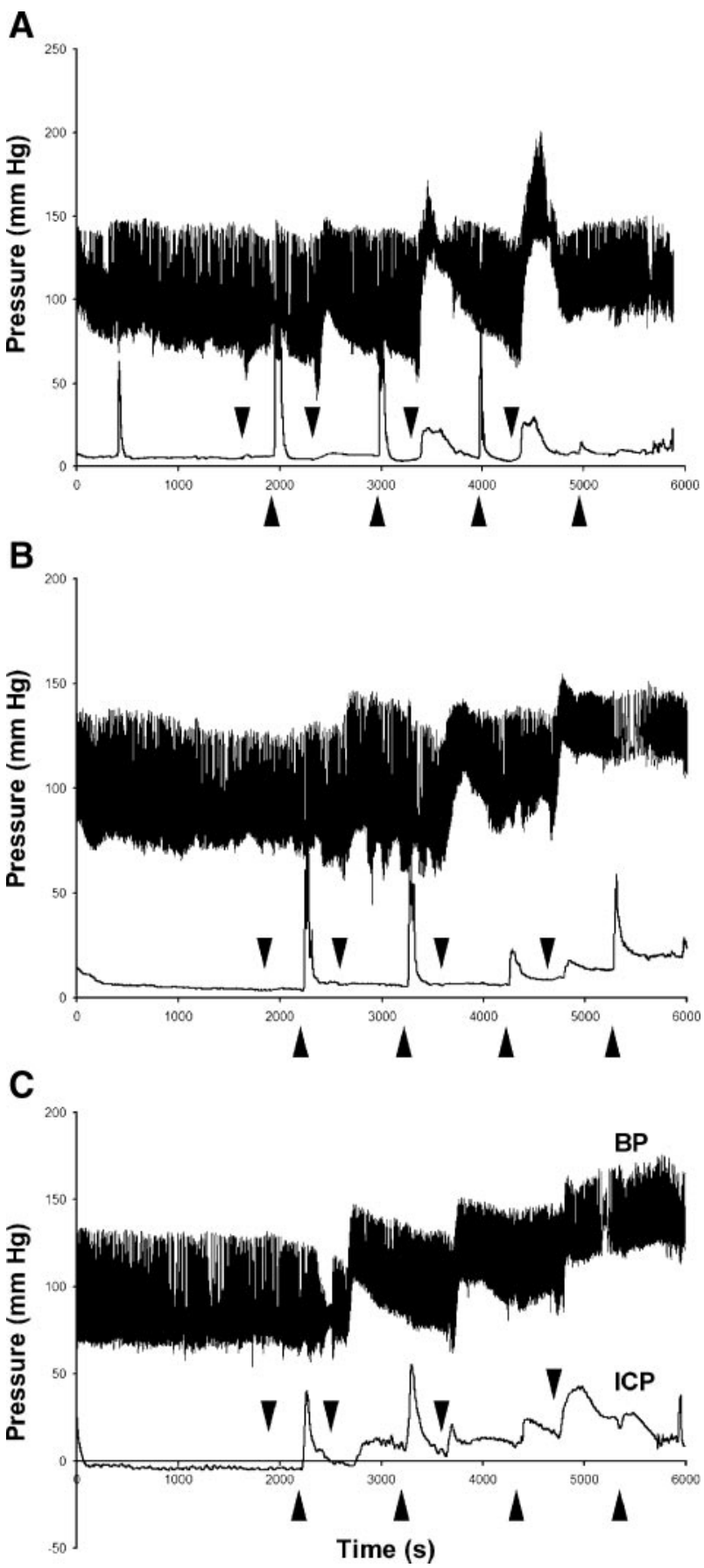

Fig. 6. Effects of the intrathecal injection of the glutamatergic agonists NMDA $(A)$ and AMPA $(B)$ BP and ICP. Each recording represents 1 experiment, carried out on a separate animal, showing the BP (top trace) and the ICP (bottom trace). Agonists were administered alone ( $A$ and $B$ ) or in combination $(C)$. Downward arrowheads (above ICP traces) represent the start of the successive intrathecal injections of 0 (leftmost arrowhead), 1, 10, and $100 \mu \mathrm{g}$ (rightmost arrowhead) of each compound. Upwards arrowheads (below $x$-axis) represent the start of electrical stimulation of the DPN $(5 \mathrm{~V}, 5 \mathrm{~Hz}, 1 \mathrm{~ms}, 30 \mathrm{~s})$.

affected significantly BP $(P<0.001$ for NMDA and $P=0.002$ for AMPA). BP was not affected by the combination of the two agonists at any concentration. ICP was not affected by either drug, alone or in combination.
Table 1. Effects of the glutamatergic agonists NMDA and AMPA upon BP and ICP pressures in anesthetized rats in the absence of dorsal penile nerve stimulation

\begin{tabular}{lccc}
\hline \hline \multicolumn{1}{c}{ Compound } & Dose, $\mu \mathrm{g}$ & BP, $\mathrm{mmHg}$ & ICP, $\mathrm{mmHg}$ \\
\hline NMDA & 0 & $78 \pm 9$ & $11 \pm 2$ \\
& 1 & $88 \pm 6$ & $13 \pm 3$ \\
& 10 & $107 \pm 6^{*}$ & $17 \pm 3$ \\
AMPA & 100 & $125 \pm 8 \ddagger$ & $53 \pm 21^{*}$ \\
& 0 & $57 \pm 5$ & $9 \pm 1$ \\
& 1 & $59 \pm 4$ & $9 \pm 1$ \\
NMDA+AMPA & 10 & $76 \pm 3 \dagger$ & $14 \pm 2 \dagger$ \\
& 100 & $100 \pm 9 \ddagger$ & $21 \pm 2 \ddagger$ \\
& 0 & $78 \pm 6$ & $8 \pm 6$ \\
& 1 & $82 \pm 8$ & $19 \pm 6^{*}$ \\
& 10 & $102 \pm 9 \dagger$ & $31 \pm 6 \dagger$ \\
& 100 & $126 \pm 4 \ddagger$ & $54 \pm 44 \ddagger$ \\
\hline
\end{tabular}

Values are means \pm SE of 7 determinations for NMDA and AMPA alone and 6 determinations for the combined administration of both agonists. ${ }^{*} P<$ $0.05 ; \dagger P<0.01 ; \ddagger P<0.001$ vs. control value (1-way ANOVA with repeated measures, Holm-Sidak method). BP, blood pressure; ICP, intracavernous pressure.

Their effects on ICP/BP ratio are shown in Fig. 8. A significant dose effect of the glutamatergic agonist NMDA alone was observed $[F(3,27)=18.497, P<0.001]$, attributable to the two higher doses $(10$ and $100 \mu \mathrm{g}$ vs. control: $P<$ 0.001). No such effect was observed either with the glutamatergic agonist AMPA $\left(\chi^{2}=7.087, \mathrm{df}=3, P=0.069\right)$, or with the combined administration of NMDA and AMPA $[F(3,23)=$ $3.239, P=0.052]$. The latency of the response to DPN stimulation was neither affected by NMDA nor by AMPA, injected either alone or in combination (data not shown).

\section{DISCUSSION}

Previous reports have established that the stimulation of the DPN elicits ICP rises in anesthetized rats, either intact or T8 spinalized $(27,29,35)$. Our present study, by exploring a wide range of stimulation parameters (amplitude, pulse width, frequency, and duration), confirms and extends these observations

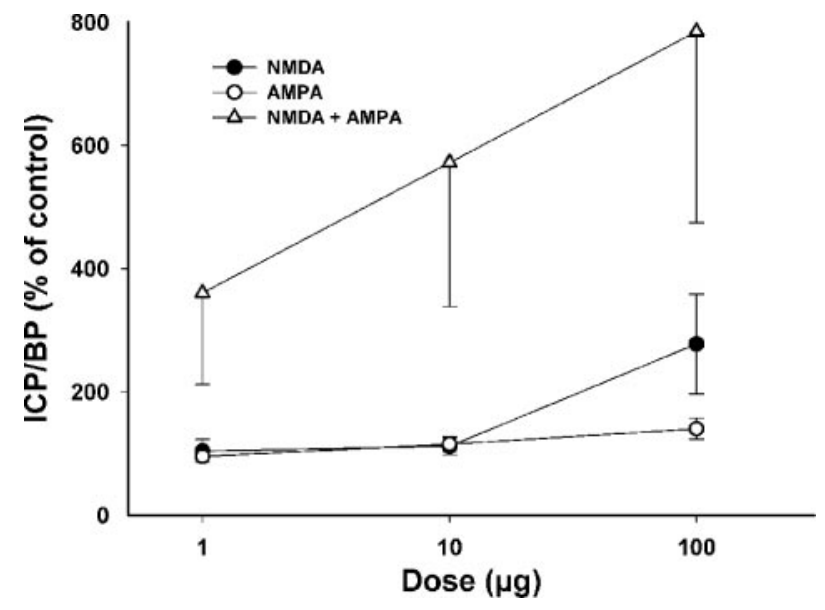

Fig. 7. Effects of the glutamatergic agonists NMDA and AMPA on the ICP/BP ratio in the absence of DPN stimulation. Data are expressed as the percentage of the control value of the ICP/BP ratio (measured after vehicle injection). These control values were $0.151 \pm 0.028(n=7)$ for NMDA, $0.173 \pm 0.026(n=7)$ for AMPA, and $0.133 \pm 0.055(n=6)$ for NMDA+AMPA. 
Table 2. Effects of the glutamatergic agonists NMDA and $A M P A$ upon BP and ICP pressures in anesthetized rats during DPN stimulation

\begin{tabular}{lrcc}
\hline \hline \multicolumn{1}{c}{ Compound } & Dose, $\mu \mathrm{g}$ & BP, $\mathrm{mmHg}$ & ICP, $\mathrm{mmHg}$ \\
\hline NMDA & 0 & $87 \pm 6$ & $98 \pm 22$ \\
& 1 & $94 \pm 8$ & $74 \pm 11$ \\
& 10 & $91 \pm 6$ & $55 \pm 12$ \\
AMPA & 100 & $124 \pm 9 \neq$ & $50 \pm 17$ \\
& 0 & $67 \pm 4$ & $54 \pm 6$ \\
& 1 & $73 \pm 6$ & $49 \pm 13$ \\
NMDA+AMPA & 10 & $81 \pm 7$ & $31 \pm 5$ \\
& 100 & $110 \pm 13 \dagger$ & $58 \pm 10$ \\
& 0 & $92 \pm 6$ & $54 \pm 9$ \\
& 1 & $91 \pm 5$ & $61 \pm 8$ \\
& 10 & $102 \pm 8$ & $38 \pm 6$ \\
& 100 & $128 \pm 10$ & $56 \pm 16$ \\
\hline
\end{tabular}

Values are the mean \pm SE of 7 determinations for NMDA and AMPA alone and 6 determinations for the combined administration of both agonists. $\dagger P<$ $0.01 ; \ddagger P<0.001$ vs. control value (1-way ANOVA with repeated measures, Holm-Sidak method). DPN, dorsal penile nerve.

and provides a standardization of the stimulation paradigm, potentially useful for further investigations, including pharmacological approaches. The spinal section at the T8 level elicited three orders of consequences: 1) the range of stimulation conditions was wider, especially at low amplitudes; 2) the number of rats responding to DPN stimulation increased; and 3 ) the ICP rise was greater. We conclude that the T8 section indeed released the inhibition exerted by supraspinal nuclei, thus yielding more reliable and intense responses in a greater number of rats.

The ICP rise induced by DPN stimulation is a reflex response that involves the lumbosacral cord as the link between the DPN, its afferent limb on the one hand, and the pelvic and cavernous nerves, its efferent limbs on the other hand. Indeed, stimulation of the DPN activates a population of lumbosacral neurons (30) and elicits reflex-evoked potentials of the pelvic and cavernous nerves (35), whereas the section of these nerves abolishes the ICP rise elicited by DPN stimulation (29).

At present, the neurotransmitter that activates the parasympathetic network in the lumbosacral cord to elicit reflexive erections is still unknown, although several lines of evidence support the hypothesis that glutamate may be a candidate for this function. First, glutamate is present in the dorsal root ganglion cells innervating the bladder and rectum (15), and NMDA and AMPA glutamatergic receptor subtypes are present in the lumbosacral spinal cord, as revealed by immunohistochemistry $(8,13)$ and by in situ hybridization (37). Second, on in vitro preparations, preganglionic neurons of the sacral parasympathetic nucleus are activated by stimulation of either short interneurons (2) or of the lateral funiculus or of the dorsal gray commissure $(24,25)$ through AMPA and NMDA receptors. Finally, in anesthetized rats, the inhibition of glutamatergic transmission in the lumbosacral cord alters bladder motility $(38,39)$. Despite all these indications, no direct evidence for a role of glutamate in reflexive erections was available yet.

Our present results provide such evidence. In conscious rats, reflexive erections were depressed by D-AP5 and NBQX, antagonists of the NMDA and AMPA receptors, respectively. The number of responders was decreased, the latency of the first erection was increased, and the number of clusters and the total number of erections were diminished. We previously showed that reflexive erections are accompanied by ICP rises similar to those induced by DPN stimulation in anesthetized rats (5). In anesthetized rats, our present results reveal that the ICP rise induced by electrical stimulation of the DPN was inhibited by D-AP5 and NBQX. That these two compounds had no effect on ICP in the absence of DPN stimulation suggests that ICP is not under the control of a basal glutamatergic activity in the lumbosacral cord and, consequently, that glutamatergic circuits have to be activated for an ICP rise to occur and, in our experiments, for an inhibitory effect to be observed.

Thus, in conscious as well as in anesthetized rats, the two antagonists of NMDA and AMPA receptors inhibit the spinal triggering of reflexive erections.

This similarity between D-AP5 and NBQX is not shared for other pelvic functions controlled by the sacral parasympathetic nucleus. Sugaya and de Groat (36) showed that bladder contraction in the newborn rat is controlled by NMDA and AMPA receptors in two opposite directions. The blockade of NMDA receptors by MK-801 increases the amplitude of bladder contractions whereas that of AMPA receptors by 6-cyano-7-nitroquinoxaline-2,3-dione (CNQX) leads to the reverse effect. Thus the effect of the recruitment of NMDA or AMPA receptors seems to depend on the pelvic organ under control and suggests a functional segregation between sacral neurons controlling the bladder or the penis. In the rat, these neurons are situated in the same sacral parasympathetic nucleus. Interestingly, we recently demonstrated that the two populations of preganglionic neurons innervating the bladder and the penis, respectively, are spatially segregated in the sacral parasympathetic nucleus along the rostrocaudal axis of the spinal cord (4). This supports the idea that the anatomical distribution of the sacral preganglionic neurons contributes to their functional segregation.

Despite the overall similarity of the depressant effects of D-AP5 and NBQX on reflexive erections, these two antagonists differed slightly depending on the experimental situation. In

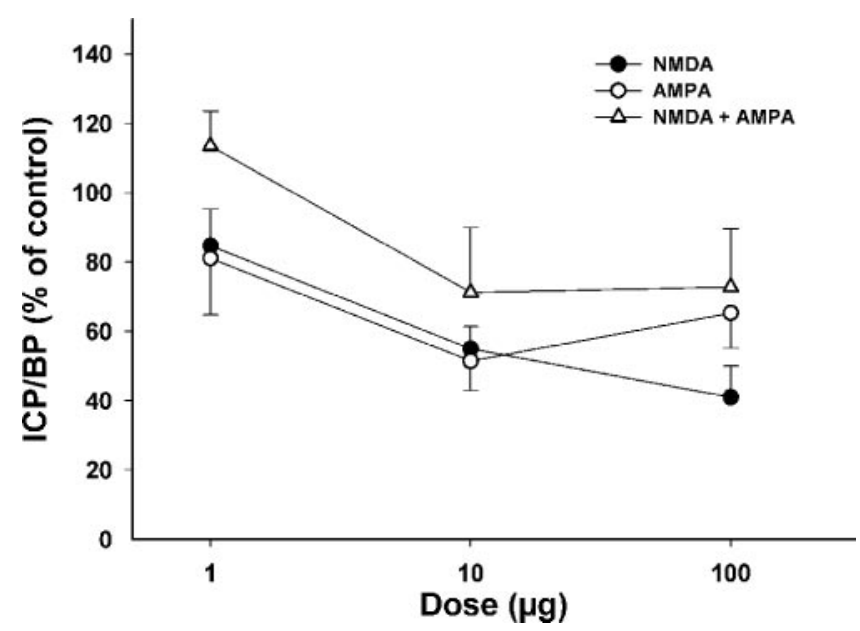

Fig. 8. Effects of the glutamatergic agonists NMDA and AMPA on the increase of the ICP/BP ratio during DPN stimulation. Data are expressed as the percentage of the control value of the ICP/BP ratio (measured during DPN stimulation in the absence of agonist). These control values were $1.19 \pm 0.24$ $(n=7)$ for NMDA, $0.87 \pm 0.06(n=7)$ for AMPA, and $0.69 \pm 0.12(n=$ 6) for NMDA+AMPA. 
conscious animals, no striking difference was recorded between them, whereas in anesthetized animals 1) D-AP5 was more potent than NBQX at inhibiting the ICP rise induced by DPN stimulation and 2) the effects of the two antagonists were not additive (Fig. 3). Indeed, the addition of NBQX did not further increase the inhibition exerted by D-AP5 alone, suggesting that the ICP rise is not mediated by the concomitant recruitment of independent NMDA and AMPA receptor-induced mechanisms. The differences between the two experimental situations should, however, be kept in mind. Although reflexive erections observed in conscious rats rely on increases of the ICP, these erections remain a complex phenomenon involving a rhythm generator controlling the frequency of erection clusters. Comparatively, ICP rises measured in anesthetized rats remain single events directly related to DPN stimulation. The interesting finding here is that the glutamatergic antagonists D-AP5 and NBQX likely affect both the individual events (the ICP rises) and the complex ones (number of clusters), supporting the idea that glutamate contributes to the spinal control of penile erection.

This conclusion is further strengthened by the effects of the glutamatergic agonists AMPA and NMDA. Individual recordings of ICP (Fig. 6 and Table 1) indicate that both of them significantly increased the penile pressure. This result is not due to a simple action on general arterial blood pressure because the ICP/BP ratio also significantly increased on injection of increasing doses of the combined agonists (Fig. 7). Thus both the inhibition by glutamatergic antagonists of the activation of a selective network mediated by DPN stimulation and the activation by glutamatergic agonists of the same network, as revealed by the increase of the ICP/BP ratio, support our hypothesis that glutamate is a potent activator of spinal proerectile pathways.

In view of the potency of glutamatergic antagonists on both reflexive erections in conscious rats and on the DPN stimulation-induced ICP rise, we expected a marked effect of agonists. Surprisingly, their effects were relatively weak. Indeed, the ICP values attained in the presence of either NMDA or AMPA reached only $40 \%$ (NMDA) or 20\% (AMPA) that of BP value. This is not attributable to an intrinsic limitation of the experimental paradigm because ICP rise on DPN stimulation reached almost the $\mathrm{BP}$ value. A possible explanation is that of the necessity of the simultaneous recruitment of both types of receptors for the activation of the proerectile spinal network. This hypothesis finds support in the observation that the modest (if any) effect of NMDA and AMPA alone was markedly enhanced by their combined administration. Thus the two subtypes of glutamatergic receptors might be associated in the spinal generation of the erectile response. In favor of this hypothesis is the lack of additivity of antagonists that exclude independent AMPA and NMDA mechanisms in the ICP rise induced by DPN stimulation. An alternative explanation, although not exclusive of the previous one, lies in the nonselectivity of glutamatergic agonists. Indeed, in our experimental conditions [and as also reported by other authors $(3,11,20)]$, they affected BP, which was rather unexpected because the spinal structures controlling blood pressure are classically located in the thoracic spinal cord. This suggests that, when administered by intrathecal route at the lumbar level, glutamatergic agonists may activate other glutamatergic circuits in addition to that of erection and notably those controlling other pelvic functions. In view of the reciprocal inhibition that the various pelvic functions exert one onto the other (e.g., micturition vs. defecation; $6,7,10$ ), the erectile function may well be the target of an inhibition exerted by other lumbosacral circuits activated by glutamatergic agonists. This interference may also contribute to explain the inhibitory effect of the agonists on the ICP rise elicited by DPN stimulation, shown in Fig. 8. Their exogenous application may have activated other circuits exerting an inhibitory action on the erectile network. A place where such an inhibitory action may occur is the primary afferent ending in the dorsal horn. Indeed, both the presence of presynaptic NMDA-R1 on primary afferent endings (18) and the glutamate release by AMPA receptors located at the central terminals of primary afferents (17) have been reported. Among these afferent fibers bearing NMDA or AMPA receptors, there are probably glutamate fibers that innervate the penis.

In conclusion, our results provide in vivo, in anesthetized as well as in conscious rats, a pharmacological demonstration of the role of the glutamatergic transmission in the modulation of reflexive erections. Erection may thus be added to the important list of excitatory actions mediated by glutamate in the central nervous system (22). In the spinal cord, primary afferents stimulation activates dorsal horn neurons, and this effect is mimicked by the application of glutamate (34). All the primary afferents that terminate in the superficial layers of the dorsal horn use glutamate as their neurotransmitter (31). In addition, it is established that glutamate plays an essential role as an excitatory neurotransmitter in the central pathways controlling the lower urinary tract of the rat (9). Thus, besides micturition, penile erection appears as another pelvic function controlled by the same neurotransmitter, glutamate, at the lumbosacral spinal level. The question rises of the recruitment of a specific network to control a given pelvic function. We already showed by three-dimensional modeling (4) that spatial topography is a means of ensuring the required specificity. Our present results suggest that a ubiquitous neurotransmitter may, in this context, exert, through its various types of receptors, a fine regulation over coordinated functions.

\section{ACKNOWLEDGMENTS}

The authors gratefully acknowledge M. Costa and B. Barbier for taking care of the animals.

\section{GRANTS}

Supported by an institutional grant from Institut National de la Recherche Agronomique to O. Rampin, R. Monnerie, N. Jérôme, and Y. Maurin, and by grant NIH-5R01MH059811-03 to O. Rampin and K. McKenna.

\section{REFERENCES}

1. Andersson KE. Pharmacology of penile erection. Pharmacol Rev 53: 417-450, 2001.

2. Araki I and de Groat WC. Unitary excitatory synaptic currents in preganglionic neurons mediated by two distinct groups of interneurons in neonatal rat sacral parasympathetic nucleus. J Neurophysiol 76: 215-226, 1996.

3. Arnolda LF, McKitrick DJ, Llewellyn-Smith IJ, and Minson JB. Nitric oxide limits pressor responses to sympathetic activation in rat spinal cord. Hypertension 36: 1089-1092, 2000.

4. Banrezes B, Andrey P, Maschino E, Schirar A, Peytevin J, Rampin O, and Maurin Y. Spatial segregation within the sacral parasympathetic nucleus of neurons innervating the bladder or the penis of the rat as revealed by three-dimensional reconstruction. Neuroscience 115: 97-109, 2002. 
5. Bernabe J, Rampin O, Sachs BD, and Giuliano F. Intracavernous pressure during erection in rats: an integrative approach based on telemetric recording. Am J Physiol Regul Integr Comp Physiol 276: R441R449, 1999.

6. Bouvier M and Grimaud JC. Neuronally mediated interactions between urinary bladder and internal anal sphincter motility in the cat. J Physiol 346: 461-469, 1984.

7. Bouvier M, Grimaud JC, and Abysique A. Effects of stimulation of vesical afferents on colonic motility in cats. Gastroenterology 98: 11481154, 1990.

8. Chambille I and Rampin O. AMPA glutamatergic receptor-immunoreactive subunits are expressed in lumbosacral neurons of the spinal cord and neurons of the dorsal root and pelvic ganglia controlling pelvic functions in the rat. Brain Res 933: 66-80, 2002.

9. De Groat WC and Yoshimura N. Pharmacology of the lower urinary tract. Annu Rev Pharmacol Toxicol 41: 691-721, 2001.

10. Floyd K, McMahon SB, and Morrison JF. Inhibitory interactions between colonic and vesical afferents in the micturition reflex of the cat J Physiol 322: 45-52, 1982.

11. Garcia MC and Celuch SM. Participation of nitric oxide and $N$-methylD-aspartic acid receptors in the pressor response to intrathecal injected noradrenaline at the spinal cord of the rat. Neurosci Lett 329: 125-128, 2002.

12. Giuliano F, Bernabe J, Jardin A, and Rousseau JP. Antierectile role of the sympathetic nervous system in rats. J Urol 150: 519-524, 1993.

13. Gougis S, Prud'homme MJ, and Rampin O. Presence of the $N$-methylD-aspartic acid R1 glutamatergic receptor subunit in the lumbosacral spinal cord of male rats. Neurosci Lett 323: 224-228, 2002.

14. Hart BL. Testosterone regulation of sexual reflexes in spinal male rats. Science 155: 1283-1284, 1967.

15. Keast JR and Stephensen TM. Glutamate and aspartate immunoreactivity in dorsal root ganglion cells supplying visceral and somatic targets and evidence for peripheral axonal transport. J Comp Neurol 424: 577-587, 2000 .

16. Kozlowski CM, Bountra C, and Grundy D. The effect of fentanyl, DNQX and MK-801 on dorsal horn neurones responsive to colorectal distension in the anaesthetized rat. Neurogastroenterol Motil 12: 239-247, 2000.

17. Lee CJ, Bardoni R, Tong CK, Engelman HS, Joseph DJ, Magherini PC, and MacDermott AB. Functional expression of AMPA receptors on central terminals of rat dorsal root ganglion neurons and presynaptic inhibition of glutamate release. Neuron 35: 135-146, 2002.

18. Liu H, Wang H, Sheng M, Jan LY, Jan YN, and Basbaum AI. Evidence for presynaptic $N$-methyl-D-aspartate autoreceptors in the spinal cord dorsal horn. Proc Natl Acad Sci USA 91: 8383-8387, 1994.

19. LoPachin RM, Rudy TA, and Yaksh TL. An improved method for chronic catheterization of the rat spinal subarachnoid space. Physiol Behav 27: 559-561, 1981.

20. Maiorov DN, Krenz NR, Krassioukov AV, and Weaver LC. Role of spinal NMDA and AMPA receptors in episodic hypertension in conscious spinal rats. Am J Physiol Heart Circ Physiol 273: H1266-H1274, 1997.

21. Marson L, Platt KB, and McKenna KE. Central nervous system innervation of the penis as revealed by the transneuronal transport of pseudorabies virus. Neuroscience 55: 263-280, 1993.
22. Mayer ML and Westbrook GL. The physiology of excitatory amino acids in the vertebrate central nervous system. Prog Neurobiol 28: 197276, 1987.

23. McKenna KE and Nadelhaft I. The organization of the pudendal nerve in the male and female rat. J Comp Neurol 248: 532-549, 1986.

24. Miura A, Kawatani M, and de Groat WC. Excitatory synaptic currents in lumbosacral parasympathetic preganglionic neurons elicited from the lateral funiculus. J Neurophysiol 86: 1587-1593, 2001.

25. Miura A, Kawatani M, and de Groat WC. Excitatory synaptic currents in lumbosacral parasympathetic preganglionic neurons evoked by stimulation of the dorsal commissure. J Neurophysiol 89: 382-389, 2003.

26. Nunez R, Gross GH, and Sachs BD. Origin and central projections of rat dorsal penile nerve: possible direct projection to autonomic and somatic neurons by primary afferents of nonmuscle origin. J Comp Neurol 247: 417-429, 1986.

27. Pescatori ES, Calabro A, Artibani W, Pagano F, Triban C, and Italiano G. Electrical stimulation of the dorsal nerve of the penis evokes reflex tonic erections of the penile body and reflex ejaculatory responses in the spinal rat. J Urol 149: 627-632, 1993.

28. Rampin O, Bernabe J, and Giuliano F. Spinal control of penile erection. World J Urol 15: 2-13, 1997.

29. Rampin O, Giuliano F, Dompeyre P, and Rousseau JP. Physiological evidence of neural pathways involved in reflexogenic penile erection in the rat. Neurosci Lett 180: 138-142, 1994.

30. Rampin O, Gougis S, Giuliano F, and Rousseau JP. Spinal Fos labeling and penile erection elicited by stimulation of dorsal nerve of the rat penis. Am J Physiol Regul Integr Comp Physiol 272: R1425-R1431, 1997.

31. Rustioni A and Weinberg RJ. The somatosensory system. In: Handbook of Chemical Neuroanatomy, edited by Bjorklund A, Hokfelt T, and Swanson LW. Amsterdam: Elsevier, 1989, p. 219-321.

32. Sachs BD and Garinello LD. Spinal pacemaker controlling sexual reflexes in male rats. Brain Res 171: 152-156, 1979.

33. Schmidt MH, Valatx JL, Sakai K, Debilly G, and Jouvet M. Corpus spongiosum penis pressure and perineal muscle activity during reflexive erections in the rat. Am J Physiol Regul Integr Comp Physiol 269: R904-R913, 1995.

34. Schneider SP and Perl ER. Comparison of primary afferent and glutamate excitation of neurons in the mammalian spinal dorsal horn. $\mathrm{J} \mathrm{Neu}$ rosci 8: 2062-2073, 1988.

35. Steers WD, Mallory B, and de Groat WC. Electrophysiological study of neural activity in penile nerve of the rat. Am J Physiol Regul Integr Comp Physiol 254: R989-R1000, 1988.

36. Sugaya K and de Groat WC. Micturition reflexes in the in vitro neonatal rat brain stem-spinal cord-bladder preparation. Am J Physiol Regul Integr Comp Physiol 266: R658-R667, 1994.

37. Tolle TR, Berthele A, Zieglgansberger W, Seeburg PH, and Wisden W. The differential expression of 16 NMDA and non-NMDA receptor subunits in the rat spinal cord and in periaqueductal gray. $J$ Neurosci 13: 5009-5028, 1993.

38. Vera PL and Nadelhaft I. MK-801, a non-competitive NMDA receptor antagonist, produces facilitation of the micturition reflex in awake, freelymoving rats. Neurosci Lett 134: 135-138, 1991.

39. Yoshiyama M, Roppolo JR, and de Groat WC. Effects of LY215490, a competitive $\alpha$-amino-3-hydroxy-5-methylisoxazole-4-propionic acid (AMPA) receptor antagonist, on the micturition reflex in the rat. J Pharmacol Exp Ther 280: 894-904, 1997. 